\title{
Philosophiques
}

\section{Le contractualisme et la question des nationalités}

\section{Lukas K. Sosoe}

Volume 19, numéro 2, automne 1992

Une nation peut-elle se donner la constitution de son choix?

URI : https://id.erudit.org/iderudit/027189ar

DOI : https://doi.org/10.7202/027189ar

Aller au sommaire du numéro

Éditeur(s)

Société de philosophie du Québec

ISSN

0316-2923 (imprimé)

1492-1391 (numérique)

Découvrir la revue

Citer ce document

Sosoe, L. K. (1992). Le contractualisme et la question des nationalités.

Philosophiques, 19(2), 29-50. https://doi.org/10.7202/027189ar d'utilisation que vous pouvez consulter en ligne.

https://apropos.erudit.org/fr/usagers/politique-dutilisation/ 


\title{
LE CONTRACTUALISME ET
}

\section{LA QUESTION DES NATIONALITÉS}

\author{
par \\ Lukas K. Sosoe
}

La question de savoir si une nation peut se donner la constitution de son choix peut paraître fort insolite tant sa réponse semble évidente. A y regarder de très près, il n'en est rien.

Cétait en I79r que l'écrivain allemand, Justus Möser, posait une semblable question dans son ouvrage Patriotischen Phantasien à propos des événements politiques qui se déroulaient en pays de France: "Quand et comment, se demandait-il, une nation peut-elle changer sa Constitution? »Il répondit par la négative, non pas tant parce que l'idée de souveraineté lui paraissait absurde, mais parce que sa conception organiciste et historiciste, pour ne pas dire romantique, de la nation ne le lui permettait tout simplement pas de répondre par l'affirmative.

Il est tentant de croire que c'est le temps qui nous sépare de cet auteur qui explique, sans toutefois justifier, le refus de ce qui nous paraît aller de soi. Et l'on aurait donc tendance à expliquer le caractère négatif de sa réponse uniquement par un argument historique. Ce que cet argument historique aurait de problèmatique et d'insuffisant s'impose de lui-même à la lumière de notre problème national, celui du Ouébec.

Cest donc pour montrer toute la complexité de la question du changement constitutionnel et de la souveraineté que je voudrais montrer, en m'inspirant de la demarche de Justus Möser et celle des auteurs qui argumenteraient de la même façon, ce en 
quoi, au plan philosophique, le problème de la souveraineté nationale québécoise ne paraît pas d'une évidente clarté et qu'il semble, au contraire, prendre la forme d'une revendication paradoxale.

Revendication paradoxale d'abord, parce qu'à suivre les deux concepts de nation, le discours sur la souveraineté québécoise s'apparente beaucoup à la logique romantique de la nation ${ }^{\mathrm{I}}$, logique au nom de laquelle on voit mal comment on pourrait parler de changement constitutionnel ou même d'indépendance. Situation paradoxale ensuite parce qu'on ne saurait, dans la logique qui est celle d'une conception romantique de la nation, convoquer l'idée même d'une cohabitation avec d'autres, notamment des anglophones québécois et des allophones. Situation paradoxale, enfin, car qui dit autonomie ou souveraineté présuppose qu'il existe des droits collectifs, des droits pour des groupes ou des collectivitès, ce qui dans une perspective moderne individualiste du droit reste encore largement à démontrer.

Ainsi précisé, notre problème se situe au plan purement philosophique et entend attirer l'attention sur des difficultés purement théoriques qui sont liées à la revendication de la souveraineté dans le cadre de deux conceptions différentes et opposées de la nation. Il est loin d'être un plaidoyer pour ou contre la souveraineté en général, celle du Québec en particulier, mais entend uniquement soulever un certain nombre de questions relatives à la défense de l'idée même d'autonomie ou de la sécession qui, à partir de la description de la nature du nationalisme québécois, participent plutôt d'une logique romantique que moderne, contractualiste.

Il s'agit, répétons-le encore une fois, non pas d'une position pour ou contre la revendication de la souveraineté, mais d'une réflexion philosophique sur des problèmes liés à la nature d'un nationalisme particulier au sein d'une société moderne contemporaine. Penser le pour et le contre pourrait, certes bien, être un exercice intéressant, qui hélas en définitive, doit fatalement s'incliner devant l'histoire qu'un peuple veut se donner à vivre et la passion qui le porte irrésistiblement vers le devenir de son destin. Peut-ètre devrions-nous soutenir, dans ce contexte

I. L'expression est utilisée ici dans le sens allemand du terme, celui-là qu'on peut faire remonter à Herder. Concernant le sens plus précis de la notion, voir Barrett-Kriegel, L'Etat et les esclaves, Alain Finkelkraut, La défaite de la pensée, Folio, Essais, Paris NRF Gallimard, 1987. 
précis, contre Hegel, que l'histoire du monde n'est pas le tribunal du monde et dire à la suite de Fichte que le problème du droit disons, le projet national - ne ressortit absolument pas au «tribunal de l'histoire ${ }^{2}$.

Mais alors qu'est-ce que la logique romantique de la nation et qu'est-ce qui autorise que soit interprété le nationalisme québécois comme obéissant à une logique romantique?

Contrairement à la conception moderne de la nation selon laquelle la nation est une association de personnes, unies par des liens contractuels, manifestant ainsi leur libre volonté de vivre sous les mêmes lois ${ }^{3}$, l'idée romantique de la nation se définit avant tout par un certain nombre d'éléments dont la naissance, les liens de sang, la race ou l'ethnie, l'histoire commune, la langue, la culture, etc...On en est membre, on ne le devient pas par une libre adhésion à des principes de coexistence d'une communauté. La nation au sens romantique du terme śénonce essentiellement comme une identité plus ou moins close sur ellemême et repose sur des liens organiques naturels. Cest avant tout une communauté vivante, historiquement advenue, de personnes unies par la même langue, la même culture, les mêmes origines, trois élements perçus comme étant des biens communs autour desquels se cristallise l'identité du groupe. Cest nécessairement une communauté qui manifeste sa différence, c'est-à-dire, ce qui la distingue des autres. Cest pourquoi la nation, au sens romantique du terme, renvoie à l'idée de nationgénie, d'âme collective, à une vision organiciste et historiciste. La nation a un contenu particulier que reprendra le discours qui l'énonce: ce qui, de toute évidence, l'èloigne de la pensée contractualiste, de l'idée républicaine.

Parce qu'il est justement éloigné de l'idée moderne de la nation, le nationalisme québécois se présente comme un nationalisme romantique dont les élements constitutifs sont la langue et la culture françaises, l'histoire de cette culture en Amérique du Nord et surtout la conscience très forte d'appartenance à cette histoire, à cette culture, conscience que nul ne saurait vouloir ignorer. Il apparaît, bien évidemment, que l'identité québécoise qui ici s'inscrit dans l'histoire québécoise représente une identité non construite. Elle ne correspond nullement à une construction à partir d'individus volontairement associés. Elle

2. Fichte, Sümtliche Werke, éd. I. H. Fichte, VI, p. 58.

3. Voir Finkelkraut, Op.cit. 
n'est pas une identité que l'on choisit, dans la mesure où nul ne peut choisir d'être "Québécois pure laine ». Même si, dans les discours, la nécessité d'une ouverture se trouve reconnue - et dans les faits elle l'est indéniablement - l'identité québécoise ne représente pas un moment volontariste, un moment de décision, mais se présente comme une entité organique, historique, donc une « entité close ». La question se pose de savoir comment une telle nation peut vouloir se donner la Constitution de son choix?

Question redoutable si tant est que l'organicisme et l'historicisme s'opposent au décisionnisme, à toute tentative volontariste. Question difficile, dont la réponse n'est pas aisée à trouver, car le contexte géopolitique dans lequel se déploie l'identité nationale québécoise, à savoir le Canada, représente une entité moderne, extérieure à l'identité nationale québécoise. Par rapport à celle-ci on peut la concevoir comme une entité moderne dans le sens volontariste et républicain du terme. Même s'il est possible de repérer des moments ou aspects romantiques, ce qui semble définir le Canada cest avant tout l'idée d'un État libéral démocratique. On comprend aisément la controverse autour de la reconnaissance d'une nation distincte en faveur du Québec. Mais parler de nation distincte - et peu importe comment la chose elle-même se conçoit, - c'est faire explicitement ou implicitement référence à un réaménagement constitutionnel, donc faire usage d'un discours de type contractualiste, difficilement compatible avec la nature même du discours identitaire québécois. Il y a incompatibilité parce que parler le langage contractualiste constitutionnel en vue de prendre en compte les intérêts des contractants ou même en vue de redéfinir les termes de l'association c'est exclure, donc évacuer, l'aspect dominant du discours national québécois. Il y a incompatibilité parce que les prémisses de la logique qui exigerait un réaménagement constitutionnel éventuel sont de type contractualiste et ne pourraient se comprendre que dans une logique individualiste à laquelle elles sont réductibles. Elles semblent donc s'opposer à la nature d'une identité nationale, collective, définie en termes romantiques. Il s'ensuit donc que la revendication d'une socièté distincte dans le cadre d'une entité républicaine comme le Canada n'est pas compatible avec la nature romantique de l'identité québécoise.

Pour plus de clarté, la présente démarche peut se résumer de la manière suivante: 
I) les ëléments constitutifs de l'identité québécoise sont de nature organique, historique; donc de nature nécessairement différente d'un ordre politique de type moderne, individualiste, libéral et démocratique. Puisqu'il est moderne et individualiste, l'ordre démocratique reste indifférent aux éléments constitutifs de l'identité québécoise, dans la mesure où celle-ci n'est pas définie en référence au système de la somme des préférences individuelles compatibles pour tous. L'ordre social et politique correspondant à ce qu'une identité romantique justifierait n'admet pas une intervention de la volonté humaine.

2) dans la mesure où il demeure un Etat démocratique, le Canada se présente comme une entité moderne, donc opposée ou indifférente à toute définition romantique, à toute définition historiciste. En tant que telle, son existence comme groupe de personnes associées, vivant sous une même législation, ne dépend que du vouloir des individus. En cela la Constitution canadienne peut changer à tout moment sans que ne soit remise en cause la définition moderne, aussi longtemps que ce changement ne soppose radicalement aux principes libéraux, démocratiques. Le processus de ce changement doit moins, au plan de la logique proprement moderne, à une transformation des éléments définissant une identité nationale qu'épuiserait la revendication d'une identité particulière.

3) or, par une étrange ruse de la raison, la reconnaissance d'une telle association et la volonté de négocier avec elle signifie qu'on accepte ce qu'elle est et ce que son existence implique, à savoir l'indifférence par rapport à une identité romantiquement définie.

4) négocier avec cet ordre moderne, ce qui signifie le reconnaître comme partenaire, exige donc que notre identité québécoise soit réduite à la somme des intérêts de la pluralité d'individus québécois ou soit mise au même plan que ceux de provinces et de groupes n'ayant pas la même perception d'eux-mèmes étant donné qu'ils ne forment pas une entité comparable à celle de l'identité québécoise.

5) ce processus ne signifie rien d'autre, au plan proprement philosophique, que l'abandon de la manière dont le Québec se définit comme nation québécoise. Nous ne nous percevons pas comme une somme d'individus dont les 
intèrêts ou les préférences se trouvent par hasard être des intérêts et préférences culturelles et linguistiques. Nous sommes une nation irréductible à la somme de ses individus.

6) Au plan de ce qui constitue notre identité - et c'est bien là la conclusion de cette première partie de notre démarche vouloir être reconnu comme nation distincte, c'est vouloir la mort nationale, c'est-à-dire vouloir la réduction de la conscience nationale à une multitude de consciences individuelles.

Contrairement à ce que l'on pourrait penser, notre démarche n'est pas aussi ètrange ni absurde qu' on peut le penser. On pourrait même la rendre plus accessible en partant du fait qu'étant de part ses présupposés moraux individualistes, l'État moderne ne saurait reconnaitre de droits que ceux qui se laissent réduire à des intérêts personnels et non à des intérêts communs, à des groupes qui composent la société. Point n'est besoin d'évoquer dans ce contexte la critique bien connue des communautariens, tels Michael Sandel ${ }^{4}$, Charles Taylor ${ }^{5}$ et Alasdair MacIntyre ${ }^{6}$, selon laquelle la démocratie libérale est fondamentalement incapable de prendre en compte le bien commun d'une communauté nationale en vertu de ses prémisses individualistes.

La présente conclusion n'est cependant pas incontournable. On pourrait lui opposer au moins un argument. Il sénonce comme suit: la reconnaissance par un Etat moderne démocratique de certains droits des groupes ou des collectivités existe effectivement. Donc le Québec peut et doit être reconnu comme entité culturelle qui veut préserver sa culture. Il n'est donc nullement question de la traiter comme une pluralité d'individus qui se trouvent par hasard poursuivre les mêmes interrêts. De plus il y a le droit des peuples à l'autodétermination. Par conséquent le problème national québécois pourrait bien se concevoir, non pas en termes d'une pluralité d'individus, mais plutôt comme un problème des droits des groupes. On peut également le comprendre dans la perspective d'un droit à

4. Michael Sandel, Liberalism and the Limits of Justice, New York, Ig82.

5. Charles Taylor, "Quiproquos et malentendus: le dèbat communautaireslibéraux $»_{\text {in }}$ Lieux et transformations de la philosophie, Presses universitaires de Vincennes, 1991, pp. 171-202.

6. Alasdair Macintyre, After Virtue: A Study in Moral Theory, Notre Dame, Indiana, Ig84; "Is Patriotism a Virtue? », University of Kansas, Department of Philosopy, The Lindley Lecture, March 26, Ig84. 
l'autodétermination des peuples. Dans ce sens, le fait que la sociète distincte poserait des problèmes n'est que fort heureux. Son impossibilitê théorique nous permettra de radicaliser notre point de vue. Il ne s'agit plus de la reconnaissance de notre caractère distinct au sein du Canada, mais bien de notre reconnaissance comme État souverain, donc de la reconnaissance de notre droit en tant que groupe ou nation à la sécession en vue de nous donner les moyens d'une meilleure gestion de notre destin.

Mais alors que veut dire le droit des peuples à l'autodétermination? Qui désigne-t-on ici par peuple? De plus supposer qu'il existe des droits pour des collectivités et qu'une socièté démocratique doit reconnaitre ces droits, c'est bien là affirmer ce qu'il faut d'abord démontrer. Il faut donc démontrer en quoi ces droits ne sont pas réductibles à des droits individuels. La question à laquelle nous essaierons de répondre est donc la suivante: existe-t-il en démocratie des droits de groupes qui ne sont pas réductibles à des droits individuels?

Le droit des peuples à l'autodétermination est avant tout un concept, mieux encore un slogan politique, que les Nations Unies ont créé pour soutenir des velléités d'indépendance, dans les pays du Tiers-Monde, en particulier. Cest un slogan qui, comme tous les slogans, n'a pas tout le mérite de la clarté. On peut tout d'abord le comprendre dans un sens très fort et dans un sens faible.

Au sens fort, le droit des peuples à l'autodétermination correspond au principe normatif du nationalisme. Comme le souligne A. Buchanan, à la suite de Gellner, « le principe normatif du nationalisme stipule que tout « peuple » a droit à son État et que les limites des frontières culturelles (ethniques) et politiques doivent coïncider. Il s'agit donc nécessairement d'une indépendance totale, d'une souveraineté totale de toute collectivité qui se reconnaîtrait comme peuple ${ }^{7}$.

Comme on le soulignait, le concept de peuple n'est pas plus clair que le droit qui lui est ici revendiqué. De plus, à voir le nombre de peuples qu'il y a sur terre, à supposer même que d'autres peuples, sous la poussée de l'èmergence de nouvelles entités politiques, ne se decouvrent pas subitement un sentiment d'appartenance pouvant justifier leur revendication d'indépendance, le principe normatif du nationalisme donnerait lieu non

7. Allen Buchanan, Secession. The Morality of Political Divorce from Fort Sumter to Lithuania and Quebec, Boulder, Colorado, Westview Press, 1990, p. 48. 
seulement à une fragmentation politique illimitée, mais encore les coûts matériels et moraux de sa réalisation seront prohibitifs.

Même dans un sens très faible, le droit des peuples à l'autodétermination n'est pas clair. Qui plus est, on peut lui substituer un ensemble de mécanismes constitutionnels et politiques qui en rendent l'usage inutile. Nous pouvons donc suivre Buchanan quand il part de l'hypothèse que le recours moral au principe de l'autodétermination « dépend précisément de son caractère vague $»^{8}$. C'est une sorte de bouche-trou pour plusieurs principes possibles définissant des formes et des degrés variés d'indépendance.

Mais alors, si le concept d'autodétermination pose plus de problèmes qu'il n'en résout, il ne reste en dernier ressort qu'une revendication fondée sur le droit des groupes à la préservation de leur culture, de leur identité. La question est de savoir si la notion de droits collectifs a un sens dans le contexte d'une théorie libérale, démocratique, fondée avant tout sur des préférences individuelles. Dans quelle mesure peut-on parler de droits collectifs au développement et à la préservation de sa culture, droits qui ne sont pas réductibles à des droits individuels?

L'idée de droits collectifs a èté récemment encore défendue par des auteurs tels que Buchanan et, avant lui, par Will Kimlycka. L'hypothèse est que, dans certaines circonstances, une collectivité a besoin de droits spéciaux en vue de préserver sa culture. Il s'agit plus précisément de connaitre les formes de contrôle dont une collectivité peut disposer et si ces formes de contrôle sont suffisantes pour accorder à ces collectivités, dont la culture est menacee, la protection dont elles ont besoin.

Selon Kimlycka, être membre d'une communauté culturelle est vital pour l'individu. La culture offre de multiples choix à l'individu. Sans elle, l'individu ne saurait maitriser les multiples possibilités qui s'offrent à lui, parce que la culture sert à « relier dans un tout cohérent ce qui autrement demeurerait des buts fragmentaires »; elle offre des idéaux de plénitude et de continuité, non seulement à travers les stades de la vie humaine mais pendant des générations. Sans le contexte d'un choix doué de sens, fourni par la culture, l'individu pourrait sentir que rien ne vaut la peine d'être fait ${ }^{9}$. Bref l'individu arriverait à manquer d'horizon de sens.

8. Allen Buchanan, Op.cit., P. 5o-

9. Will Kimlycka, Liberalism, Communily and Culture, Oxford, 1989, chapitre to. 
Ce que cet argument a d'individualiste saute aux yeux. Parce qu'il est individualiste, il réduit également le problème des droits collectifs, le problème national à la somme des possibilités d'autoréalisation de l'individu. Même si les valeurs et choix de celui-ci appartiennent à l'horizon culturel d'une communauté, c'est au nom des droits individuels et non des droits d'une communauté culturelle que s'effectue le choix des valeurs nécessaires à la réalisation des fins. On voit mal comment, sur la base de cet argument, on peut parler de droits accordés à une collectivité ou à un groupe de développer sa culture ou de préserver cette culture du danger de disparaître. En d'autres termes, même si la culture en tant que telle n'est pas une chose individuelle, ce n'est pas à la collectivité qui la vit en tant que collectivité que des droits sont reconnus, mais aux individus qui la composent. on comprend donc la remarque de Buchanan qui dit que Kimlycka n'a pas discuté de droits collectifs, puisque la justification qu'il donne des droits des minorités, en vue de défendre leur culture, consiste en la valeur individuelle d'étre membre d'une culture ${ }^{\mathrm{IO}}$. Bref les droits des minorités proposés par Kimlycka sont des droits, des droits d'un groupe de restreindre les libertés individuelles mais en faveur des individus dans le groupe ${ }^{\text {II }}$.

Mais si la tentative de Kimlycka demeure tributaire d'une pensée individualiste, qu'en est-il de celle de Buchanan?

Bien qu'il déplore le fait que la démocratie libérale ne reconnaisse pas le droit des groupes comme droits moraux fondamentaux ou comme droits constitutionnels, on doit se mettre à l'évidence qu'on ne trouve nulle part dans l'ouvrage de Buchanan la démonstration qu'il existe bel et bien des droits collectifs. Ce dont l'absence est dèplorée chez Kimlycka, à savoir l'existence de droits collectifs, est affirmé sans être démontré par Buchanan. Mais ce n'est pas l'affirmation qui nous intéresse. Nous voulons savoir s'il existe des droits collectifs et comment une théorie libérale démocratique peut en rendre compte sans s'opposer à ses propres prémisses.

Il faut donc conclure, du moins provisoirement et jusqu'à preuve du contraire, que les droits collectifs ne peuvent pas se défendre sans difficultés dans le cadre d'une théorie libérale démocratique, que seuls les individus peuvent avoir des droits et que parler de la souveraineté d'une nation en vue de défendre sa

Io. Allen Buchanan, Op.cit., p. 39 .

II. Ibid., p. 40 . 
culture n'a de sens que si cette souveraineté est formulable ou traduisible en termes de préférences individuelles ou d'intėrêts individuels. Or le discours nationaliste est un discours qui ne se réfère ni au bien individuel ni à une somme de biens individuels. Vouloir réduire le discours d'une entité collective à la somme des préférences de ses éléments constitutifs individuels, c'est le vider de sa substance même. Est-ce à dire que la revendication de la souveraineté nationale ne se justifie d'aucune manière? Au plan de la justification philosophique d'un ordre libéral démocratique et non dans un système quelconque de droit positif (y compris des Chartes des droits et des libertés), l'individu demeure la seule valeur irréductible au nom de laquelle un changement constitutionnel est légitime. Ce plan de justification philosophique n'admettrait des droits collectifs que si ceux-ci sont le choix éclaire des individus eux-mêmes. Peu importe la culture à laquelle ces individus appartiennent. De plus, accorder des droits, dans un État libéral-démocratique à une catégorie de personnes, pourrait aller contre le principe du traitement égal au plan juridique.

Une telle thèse ne semble offrir aucun argument rationnel en faveur de la souveraineté en vue de la préservation de la culture d'une collectivité: si la reconnaissance de la société distincte ne trouve pas de justification morale, ne reste donc que la sécession. Le Québec est une nation. Il n'y a pas de raisons moralement contraignantes qu'elle négocie son autonomie.

Si comme nous l'avons montré, l'idée de la société distincte s'oppose à la nature romantique du discours national québécois et que la voie de la souveraineté semble se présenter comme la seule issue, mais qu'elle aussi ne saurait se réduire à la somme des droits individuels, quelle autre justification pourrait-on apporter en faveur de la souveraineté? Comment penser l'idée ou la revendication de la souveraineté?

Ce ne sont ni des droits individuels ni des droits collectifs qui justifient la souveraineté d'une nation romantique. En tant qu'entité pensable uniquement en termes organicistes et historicistes, en tant qu'entité naturelle, la nation romantique n'a pas besoin de justification rationnelle pour sa souveraineté. Il en va de la logique même de ce qu'elle est en tant que nation: entité historique, fondée sur sa culture, ses origines. Vouloir chercher une justification rationnelle à la revendication de la souverainetè d'un peuple dont l'identité ne se définit pas avant tout en termes de droits, en termes d'association de gens uniquement 
désireux de vivre sous la même législation, cest méconnaitre la nature de cette revendication. Une nation n'est pas une association, ni une union quelconque. Est-ce à dire qu'elle est irrationnelle? Non plus! La revendication de la souveraineté n'est pas rationnelle, mais tout comme l'amour et beaucoup d'autres choses de la vie humaine, elle n'est pas pour autant négative, condamnable et ceci de manière fondamentale. Ce ne sont pas des droits démocratiques et autres qui font l'histoire des peuples, des nations dont l'identité correspond à une naturalité historique. Cest ici que la phrase de Fichte acquiert tout son sens: le problème de la nation ne ressortit absolument pas au tribunal de l'histoire. Toutefois accepter cette sentence c'est accepter également les limites de la philosophie politique et juridique, du moins son incapacité, dans le cadre qui est celui de la démocratie, à penser de manière satisfaisante, le nationalisme et l'identité nationale.

La meilleure illustration de cette conclusion peut se retrouver dans la pensée révolutionnaire, dans une pensée du changement constitutionnel comme événement moral ${ }^{\mathrm{I} 2}$. Cet événement sera celui d'un peuple, se definissant en tant que tel, et qui revendique sa majorite juridique. Dans la mesure où la culture est nécessaire à la vie de la nation et donc à l'affirmation de sa dignité en tant que nation, on ne peut l'empêcher de devenir souveraine sans la minoriser juridiquement au plan moral, sans empécher son autodéploiement dans l'histoire; son développement. Puisqu'il est moralement condamnable d'empêcher le libre déploiement d'un peuple, la souveraineté n'est même plus un droit à négocier, elle devient une nécessité morale, un événement moral qui doit couronner l'avènement de l'histoire d'un peuple, car comme le dit Erhard, « un peuple est coupable du fait de sa minorité en cela il n'est pas juste qu'il se révolte [...] quand on le traite comme un mineur $\gg^{23}$. Sortir de la minorité, c'est faire son histoire et apporter au monde ce que l'on est. Cest pourquoi on peut conclure avec Erhard en ces termes: « Si l'on

12. Nous partons de l'hypothèse qu'on peut contourner les difficultès qu'il y a à penser le changement constitutionnel dans le cadre d'une théorie libérale democtatique en partant d'un concept d'exigence morale qu'a un peuple ou une nation de se libérer d'une constitution qui, à ses yeux, limite ses capacités d'action, et donc sa dignité. C'est en ce sens que toute négociation serait perçue comme une négociation de sa dignité propre qui, en aucun cas, ne peut se marchander.

I3. Johann Benjamin Erhard, Sur le droil du peuple à faire la Révolution IÜber das Recht des Volkes zur Revolution], 1795, p. $9^{2}$. 
veut empêcher le peuple de s'éclairer, alors il est juste qu'il se soulève, et si les obstacles proviennent de la Constitution, il faut abroger la Constitution $\gg^{14}$.

Département de philosophie

Université de Montréal 